\title{
Mouse Mammary Tumor Virus
}

National Cancer Institute

\section{Source}

National Cancer Institute. Mouse Mammary Tumor Virus. NCI Thesaurus. Code C14235.

Type B retrovirus. Etiologic agent of mouse mammary tumors. Transmitted horizontally through the lactating mammary gland and vertically through the germline. Mechanism of tumorigenesis involves the activation of cellular int genes by promoter/enhancer insertion. 